\title{
Liberdade de expressão na internet: a concepção restrita de anonimato e a opção pela intervenção de menor intensidade ${ }^{1-2}$
}

\author{
Freedom of expression on the internet: the restrictive conception of \\ anonymity and the option for minimal intervention
}

\author{
Rafael Mafei Rabelo Queiroz ${ }^{3}$ \\ Universidade de São Paulo (São Paulo, SP, Brasil) \\ ORCID: https://orcid.org/0000-0002-5616-8780 \\ E-mail: rmrqueiroz@usp.br
}

\section{Resuimo}

Este artigo debate a concepção constitucional de anonimato, como cláusula restritiva à liberdade de expressão. A partir de pesquisa jurisprudencial no Tribunal de Justiça do Estado de São Paulo (TJSP), o artigo argumenta que uma concepção ampla de anonimato é juridicamente equivocada e danosa à liberdade de expressão, por três razões. Primeiro, porque trata como anonimato situações que são, quando muito, "pseudonimato". Segundo, porque não encontra paralelo em situações análogas que ocorrem fora do ambiente virtual. Terceiro, porque ignora que estratégias de "anonimização" muitas vezes têm finalidades legítimas. Como alternativa, o artigo defende uma concepção restrita de anonimato, que não ignora o texto da Constituição, mas tampouco a amplia de maneira desproporcional a restrição à liberdade de expressão na internet.

\footnotetext{
${ }^{1}$ QUEIROZ, Rafael Mafei Rabelo. Liberdade de expressão na internet: a concepção restrita de anonimato e a opção pela intervenção de menor intensidade. Suprema: revista de estudos constitucionais, Brasília, v. 1, n. 1, p. 241-266, jan./jun. 2021. 


\section{Palaviras-chave}

Liberdade de expressão; Anonimato; Pseudônimos; Internet; Redes sociais.

\section{Sumário}

1. Introdução. 2. Liberdade de expressão, anonimato e internet. 3. Duas concepções de anonimato. 4. Três intensidades de intervenção. 5. Como devemos interpretar a restrição constitucional ao anonimato no ambiente de internet? 6. Conclusão.

\section{Abstract}

This article debates the conception of "anonymity" in the Brazilian Constitution. Based on a research in the decisions of Court of Justice of the State of São Paulo (TJSP), the article argues that a broad conception of anonymity is legally wrong and harmful to freedom of expression, for three reasons. First, because it equates "anonymity" situations that are, at best, pseudonymity. Second, because such broad conception finds no parallel in analogous situations outside the internet. Third, because it ignores that "anonymity" often has legitimate purposes. Alternatively, the article proposes a narrow conception of anonymity: one that does not ignore the text of the Constitution, but neither disproportionately expands it to restrict freedom of expression on the Internet.

\section{Keywords}

Freedom of expression; Anonymity; Pseudonyms; Internet; Social Networks.

\section{Contents}

1. Introduction. 2. Freedom of expression, anonymity and the internet. 3. Two conceptions of anonymity. 4. Three intensities of intervention. 5. How should we interpret the constitutional restriction on anonymity in the digital environment? 6. Conclusion. 


\section{Introdução}

A Constituição de 1988 protege a livre expressão de pensamento, mas veda o anonimato. ${ }^{4} \mathrm{Na}$ doutrina, a restrição ao anonimato costuma ser explicada pelo fato de que a liberdade de expressão não é absoluta, na medida em que expressões abusivas (calúnia, difamação, ofensa discriminatória, etc.) podem lesar direitos de terceiros e são passíveis de punição ${ }^{5}$. Nessas situações, a restrição ao anonimato garantiria a possibilidade de identificar autores de ilícitos expressivos e viabilizaria as devidas reparações, que também constituem direito subjetivo de estatura constitucional (art. $\left.5^{\circ}, \mathrm{V}\right)$. Fosse o anonimato admitido, prossegue esse raciocínio, esses abusos expressivos poderiam resultar em impunidade. A identificação seria, portanto, um ônus indissociável da liberdade de expressão ${ }^{6}$. Somada à valoração moralmente negativa da expressão anônima, que associa o anonimato exclusivamente à covardia e à evasão de responsabilização, a leitura usual da restrição ao anonimato leva ao que Artur Monteiro chama de “[...] o paradigma da exigência de identificação” (MONTEIRO, 2017, p. 16).

A internet criou espaços de expressão que não existiam à época da elaboração da Constituição de 1988. Nesses espaços, a identificação ostensiva nem sempre é a regra: das caixas de comentários nos grandes portais aos perfis de paródia em redes sociais, passando por foros especificamente arquitetados para o anonimato virtual, como os chans $^{7}$, um volume grande de manifestações expressivas circula no ciberespaço ${ }^{8}$ sem $^{2}$ que saibamos, de plano, a identidade de seus autores. Em alguns casos, como os de ataques hackers ou crimes cometidos pela internet, descobrir a identidade de usuários de internet é de fato trabalhoso, exigindo mandados judiciais e atuação de peritos técnicos, com resultados incertos.

\footnotetext{
${ }^{4}$ CRFB art. 50: "IV - é livre a manifestação do pensamento, sendo vedado o anonimato;"

${ }^{5}$ Nesse sentido, Alexandre de Moraes (2020, p. 47) nos seguintes termos: "Os abusos porventura ocorridos no exercício indevido da manifestação do pensamento são passíveis de exame e apreciação pelo Poder Judiciário com as consequentes responsabilidades civil e penal de seus autores, decorrentes inclusive de publicações injuriosas na imprensa, que deve exercer vigilância e controle da matéria que divulga.".

${ }^{6}$ Virgílio Afonso da Silva (2021, p. 170-171) identifica esta interpretação como a "dominante" entre os constitucionalistas atuais. Como exemplo dessa interpretação dominante, confira-se a lição de José Afonso da Silva: "A liberdade de manifestação do pensamento tem seu ônus, tal como o de o manifestante identificar-se, assumir claramente a autoria do produto do pensamento manifestado, para, em sendo o caso, responder por eventuais danos a terceiros" (SILVA, J., 2012, p. 245),

${ }^{7}$ Chans são fóruns para interação de usuários concebida para postagens de imagens e textos simples (imageboard). Sua arquitetura
é construída de tal modo que a identificação não é compulsória, e nenhuma informação de navegação dos usuários é armazenada,
razão pela qual muitos chans se tornaram fóruns para interação em torno de assuntos polêmicos ou ilegais (hackerismo, pornografia,
neonazismo, pedofilia etc.). O conhecido grupo "hacktivista" Anonymous tira seu nome do apelido padrão que o imageboard
4Chan atribui a qualquer usuário não identificado (MASSA, 2016, p. 6).

${ }^{8}$ Utilizo a concepção de Lessig de ciberespaço: um espaço de interação humana criado por software e hardware, regido por regras jurídicas e não jurídicas, impostas tanto por instituições formais quanto pela arquitetura da linguagem de programação que o constitui (LESSIG, 2006, p. 31 et seq.).
} 
Diante de condutas ilícitas que se valem de técnicas avançadas de anonimato na internet para assegurar a impunidade de seus perpetradores, a resposta intuitiva parece clamar pela máxima restrição ao anonimato no ciberespaço. Afinal, por que gastaríamos tempo e recursos do Judiciário, do Ministério Público e da Polícia para descobrir identidades de hackers, criminosos, caluniadores e difamadores, se podemos exigir, de plano, a identificação ostensiva de qualquer interlocutor como condição jurídica para se expressar? Dado que a vedação ao anonimato já está na Constituição, seria necessário apenas adotar uma concepção de anonimato que fosse ampla o suficiente para garantir a proibição dessas formas de comunicação típicas da internet, exigindo que qualquer forma de expressão fosse ostensivamente identificada pelo real nome de seu autor, sob pena de remoção.

Mas essa alternativa pode representar riscos à legítima liberdade de expressão. Uma concepção muito ampliada de anonimato - ou seja, da restrição constitucional à lícita expressão de pensamento - acaba por colocar em risco uma série de manifestações que não são ilícitas, mas que se valem de técnicas de ocultação da identidade de seus autores. A depender de quão alargada seja nossa concepção de anonimato, podem vir a ser consideradas formas anônimas de expressão do pensamento - logo, vedadas pela Constituição - manifestações tão variadas quanto perfis de paródia que fazem crítica satírica de autoridades, fóruns de troca de experiência profissional em que funcionários pseudonimizados revelam bastidores de suas empresas, ou blogs e perfis de redes sociais nos quais cidadãos denunciam anonimamente o crime organizado em suas comunidades. As diferenças valorativas de todos esses casos, por oposição a, digamos, um chan para troca de imagens de pedofilia, são evidentes: elas são manifestações expressivas que o direito deveria proteger, e não banir, e exigem distinções que uma concepção alargada de anonimato não permite fazer. Por isso, é importante que nos esforcemos para encontrar uma concepção de anonimato que, por um lado, não negue o fato incontornável de que ele consta da Constituição como restrição ao direito de livre expressão, mas, por outro, não implique interferências demasiadas nos direitos fundamentais que podem ser protegidos ou otimizados pelo anonimato, como a liberdade de expressão, a privacidade e a proteção a dados pessoais (BONOTTO, 2017; MACHADO; DONEDA, 2020; SILVA, V., 2021, p. 170), ou mesmo a associação por meio de fóruns digitais (SOUZA, 2015).

Neste texto, defenderei que a melhor interpretação para a restrição constitucional ao anonimato é a que chamo de concepção restrita. Ao contrário de uma concepção ampla, que é desproporcionalmente restritiva à liberdade de expressão, a concepção restrita sustenta que uma manifestação feita pela internet não pode ser considerada anônima pelo simples fato de que seu autor não seja ostensivamente identificado no ato expressivo. Adicionalmente, defenderei que a mera circunstância 
de uma manifestação expressiva ser anônima, mesmo na concepção restrita aqui defendida, não autoriza qualquer intervenção judicial sobre a manifestação (v.g. remoção da postagem, bloqueio de perfil em rede social, requisição de dados do responsável pela manifestação etc.), a não ser que ela própria constitua ato ilícito, ou que tal intervenção seja necessária à investigação de outros atos ilícitos determinados e diretamente ligados ao autor da manifestação.

Este artigo sustenta uma posição normativa, i.e., uma posição sobre como uma determinada concepção de anonimato deve ser preferida a outras que eventualmente caibam dentro daquele conceito. Como corolário, sustenta também uma posição sobre como devem agir as autoridades quando thes for requerido que intervenham sobre manifestações expressivas supostamente anônimas na internet. Mas, embora normativas, essas posições não foram construídas em um vácuo empírico. Ao contrário, foram elaboradas a partir de pesquisa jurisprudencial ${ }^{9}$ envolvendo 59 litígios sobre anonimato na internet, no Tribunal de Justiça do Estado de São Paulo (TJSP), conduzida em 2019 ${ }^{10}$. Essa pesquisa anterior buscava conhecer a variedade de situações que levam conflitos sobre anonimato na internet à justiça paulista, para, então, identificar diferentes concepções de anonimato adotadas pelo TJSP na resolução desses conflitos e conhecer as possíveis respostas jurídicas dadas pelo tribunal àquelas situações. As teses sustentadas neste artigo objetivam responder a desafios jurídicos identificados naquela oportunidade.

Além desta introdução e de uma conclusão, este artigo é composto de quatro partes. Na segunda parte (Liberdade de expressão, anonimato e internet), apresento, a partir de três casos ilustrativos, os desafios da interpretação jurídica do conceito constitucional de anonimato, quando aplicado a fenômenos ocorridos na internet. $\mathrm{Na}$ terceira parte (Duas concepções de anonimato), identifico duas concepções possíveis para o conceito de anonimato e defendo que uma delas, a que chamo de restrita, é preferível à outra, a que chamo de ampla. Na quarta parte (Três modalidades de intervenção), identifico três respostas judiciais possíveis à situação de anonimato e defendo que a melhor interpretação jurídica exige intervenção mínima nas situações

\footnotetext{
${ }^{9}$ Os parâmetros da pesquisa no portal do TJSP foram os seguintes. Argumento: internet E (anônima ou anônimo ou anonimato), no campo de busca "Ementa". A data da coleta de resultados foi $1^{\circ}$ de março de 2019 e não houve limitação temporal à pesquisa. A busca retornou 65 resultados, dos quais 7 foram excluídos por impertinência temática (p. ex., julgados sobre sociedade anônima nos quais a palavra internet aparecia na ementa). Na leitura dos 58 que restaram, uma decisão (TJSP, AI 036689873.2010.8.26.0000, 7a Câmara de Direito Privado, Rel: Des. Luiz Antonio Costa, j. 17 nov. 2010), invocada como precedente em um deles, diretamente relacionava-se ao debate sobre anonimato na internet, embora não fizesse uso dos termos-chave na ementa. Essa decisão foi incluída na base de dados. Com isso, o total de acórdãos pesquisados foi de 59.

${ }^{10}$ A pesquisa foi resultado de bolsa de pesquisa da Fapesp para uma estada na Universidade de Oxford, no Reino Unido, entre fevereiro e junho de 2019. O relatório resultante dessa pesquisa é intitulado Anonimato e liberdade de expressão na internet: reflexões a partir de uma pesquisa em julgados do Tribunal de Justiça de São Paulo.
} 
de anonimato, o que equivale a dizer que uma manifestação não pode ser removida pelo simples fato de seu autor não ser ostensivamente identificado, bem como que ninguém tem o direito subjetivo de conhecer a real identidade de um ato expressivo, pois qualquer intervenção judicial sobre manifestação de autoria não identificada somente se justifica diante do caráter ilícito de seu conteúdo. Na quinta parte, que antecede as conclusões, respondo diretamente à pergunta central deste artigo, explicitando meu entendimento sobre como devemos interpretar a restrição constitucional à expressão de opiniões de maneira anônima na internet.

\section{Liberdade de expressão, anonimato e internet}

Segundo o dicionário Houaiss, anonimato é a característica do que é anônimo, e "anônimo" é tudo aquilo que vem a lume "sem o nome do autor", ou "com nome desconhecido"; é o oposto de "conhecido" ou "famoso" (HOUAISS, 2015, p. 61). A partir desse conceito, poder-se-ia dizer que os três casos relatados nos parágrafos seguintes compreendem situações de anonimato, uma vez que envolvem manifestações feitas sem o nome de seus autores, por pessoas presumivelmente desconhecidas e não famosas.

Caso 1: Fan page Celso Barros Sincero no Facebook. O médico Celso Corrêa de Barros foi presidente da cooperativa Unimed-Rio. ${ }^{11}$ Barros tornou-se conhecido além do meio médico por seu envolvimento pessoal com seu time de coração, o Fluminense Football Club, de cuja vida política se tornou personagem constante, chegando a ser seu presidente. Ao tornar-se figura publicamente vinculada ao futebol, Barros passou a receber a atenção normalmente despendida às figuras notórias da cartolagem no Brasil. Ganhou inclusive uma fan page ${ }^{12}$ no Facebook intitulada Celso Barros Sincero, de conteúdo satírico e crítico a ele. Os advogados de Barros, então, foram ao Poder Judiciário exigir a remoção da página $^{13}$. O pedido fundava-se na proibição constitucional ao anonimato: segundo eles, a impossibilidade de identificar, de plano, o responsável pela alimentação do conteúdo da página equivaleria a anonimato e, portanto, justificaria a eliminação de todo o conteúdo postado pelo perfil.

\footnotetext{
${ }^{11}$ Além de fato público e notório, a posição é informada em seu perfil na rede Linkedin: https://www.linkedin.com/in/celsobarros-35ab9b8a/?originalSubdomain=br (acesso em: 3 jun. 2019).

${ }^{12}$ Fan page é uma página criada com uma finalidade pública, em contraste com um perfil pessoal de Facebook, que, em tese, serve à interação privada com amigos, familiares e conhecidos (FACEBOOK, 2014). Fan pages podem ser páginas de negócios, associações, agremiações de qualquer tipo, ou mesmo para uma pessoa privada que quer separar seus diferentes tipos de interações. Uma autora pode ter uma fan page com seu perfil profissional, para interagir com seus leitores, e uma página pessoal fechada, para interagir com pessoas de sua intimidade. Toda fan page é administrada por um perfil pessoal, embora os usuários que navegam o Facebook não consigam ver qual é esse perfil.
}

${ }^{13}$ TJSP, AC 1083843-12.2015.8.26.0100, 4ª Câmara de Direito Privado, Rel. Des. Hamid Bdine, j. 11 ago. 2016. 
Caso 2: Relatos profissionais em portal de $R H$. Catho Online é um conhecido portal de recursos humanos na internet, que hospeda fóruns para compartilhamento de experiências profissionais. Nesses fóruns, candidatos procuram relatos de outras pessoas com experiências em empresas e vagas para as quais estejam pensando em se candidatar. Vez por outra, os comentários são negativos, expondo más práticas internas, ambiente de trabalho degradado, políticas de promoção injustas etc. Para evitar que fiquem marcados e sejam prejudicados em processos seletivos futuros, alguns dos usuários dos fóruns, embora preencham um cadastro prévio para ter acesso às funcionalidades do portal, escolhem fazer comentários públicos identificados apenas por apelidos (pseudônimos). Ao mesmo tempo, alguns gestores de recursos humanos vasculham periodicamente o portal em busca de comentários negativos sobre as empresas onde trabalham, pois temem que críticas afugentem bons candidatos e frustrem seus processos seletivos. Quando encontram comentários que julgam prejudiciais à reputação da empresa, feitos por internautas identificados por apelidos, algumas empresas solicitam ao Poder Judiciário sua remoção ${ }^{14}$. Esses pedidos fundamentam-se na restrição ao anonimato: no entender das empresas criticadas, a vedação constitucional ao anonimato exige que as críticas sejam feitas sob a verdadeira identidade de seus autores. Mesmo que o teor das postagens não extrapole os limites da manifestação legítima de opinião, a simples forma de divulgação do comentário, feito por meio de um apelido e não do nome civil ou social de seu autor, implicaria prática de ato ilícito e permitiria a remoção da manifestação.

Caso 3: vídeo no YouTube com flagrante de achaque por agente público. Um fiscal de rendas de São Paulo cobrava propina de empresas sob ameaça de lhes criar dificuldades em fiscalizações tributárias. Para fazer prova dos achaques que sofria, uma vítima filmou ocultamente a ação do fiscal. Em seguida, publicou o vídeo no YouTube, por meio de uma conta com um nome fictício. No processo administrativo disciplinar aberto contra o fiscal, ele postulou que a prova fosse descartada. Segundo sua defesa, a publicação do vídeo de forma anônima implicaria violação à restrição constitucional ao anonimato e, portanto, acarretaria a ilegalidade da prova ${ }^{15}$.

Para além do fato de serem casos reais, esses três episódios apresentam outras características em comum. De início, como já foi dito, segundo o conceito do dicionário Houaiss exposto parágrafos atrás, todos eles seriam exemplos de manifestações anônimas: as publicações não vêm acompanhadas dos nomes reais de seus autores, cujas identidades não são de outra forma desde logo conhecíveis.

\footnotetext{
${ }^{14}$ TJSP, AI 2077958-72.2016.8.26.0000, 21 a Câmara de Direito Privado, Rel. Des. Virgilio de Oliveira Junior, j. 13 mar. 2017.

${ }^{15}$ TJSP, AI 2230955-40.2016.8.26.0000, 6a Câmara de Direito Privado, Rel. Des. Percival Nogueira, j. 17 fev. 2017.
} 
Em segundo lugar, embora anônimas, todas essas manifestações têm dignidade expressiva prima facie: provêm de cidadãos autônomos no livre uso de suas faculdades comunicativas; são desprovidas de conteúdo ilícito (não contêm crimes contra a honra ou discurso de ódio); e fundamentam-se em valores que devem ser protegidos em uma sociedade democrática, tais como: o direito de crítica satírica a personalidades públicas, o direito de expressar uma opinião informada sobre uma empresa e o direito de denunciar crimes cometidos por agentes públicos. Em terceiro lugar, a "anonimização", entendida por ora apenas como ocultamento de identificação ostensiva, é uma característica central de todas elas: o perfil satírico acrescenta graça à paródia e potencializa o alcance das críticas públicas a Celso Barros; e a ocultação de identidade protege os trabalhadores que informam sobre os bastidores profissionais de suas empresas, bem como o empresário que denuncia o achaque de que é vítima, dando-lhes uma segurança sem a qual a manifestação poderia acabar inibida. Vale dizer, a "anonimização" está relacionada ora ao conteúdo expressado, ora às próprias condições de existência daquelas expressões. Finalmente, em todos os casos, o suposto anonimato das publicações é meramente relativo. Embora seus autores não sejam desde logo identificados nas publicações, eles são facilmente identificáveis com esforços mínimos de diligência junto a provedores de conexão e aplicação, que guardam, por força de determinação legal, registros de conexão à internet e acesso a aplicações que ficam à disposição do Poder Judiciário - mas apenas no caso de prática de atos ilícitos. ${ }^{16}$ Trata-se, em princípio e em todas as situações, da espécie de ocultação de identidade que resulta em anonimato meramente "superficial", "fraco" ou “relativo" (BONOTTO, 2017, p. 45; RODRIGUEZ, 2015, p. 14).

Esses casos não parecem ser aqueles que deveríamos restringir com apoio na cláusula constitucional que veda o anonimato. A despeito de uma semelhança na forma (anônima, no sentido de dicionário do termo), essas situações se distinguem de outras desprovidas de dignidade expressiva, como o compartilhamento de imagens de pedofilia em fóruns na deep web ou textos caluniadores apócrifos contra candidatos em véspera de eleições. Se nossa concepção de anonimato não consegue diferençar entre todas essas situações, isso é um problema cuja superação exige o enfrentamento de duas questões. Primeiro, como deve ser interpretado o anonimato de formas de expressão comuns na internet, à luz do dispositivo constitucional que veda o anonimato no exercício da liberdade de expressão? Devem ser consideradas anônimas e, portanto, sujeitas a restrição quaisquer manifestações que não venham acompanhadas

${ }^{16}$ Lei 12.965/2014 (Marco Civil da Internet), arts. $10 \$ 3^{\circ}$, 13 e 15. 
da identificação real de seus autores? Ou, ao contrário, o conceito de anonimato deve ser interpretado de modo mais restrito, de forma a não servir de pretexto para intervenções excessivas sobre manifestações com dignidade expressiva, merecedoras de proteção constitucional? Segundo, uma vez diante de uma manifestação anônima, como deve se dar a intervenção do Poder Judiciário? A mensagem deve ser removida do provedor de aplicação que a abriga? A conta que a postou deve ser excluída? O usuário deve ser bloqueado da plataforma que usou para se manifestar anonimamente? Devese buscar a identificação de seus autores, por meio da requisição de dados pessoais aos provedores de aplicação e conexão? A simples falta de identificação ostensiva basta para justificar alguma forma de intervenção (a identificação do autor da postagem, ao menos), ou a atuação judicial deve limitar-se aos casos nos quais o conteúdo da mensagem seja ilícito?

\subsection{O desafio do vácuo de responsabilidade}

A resposta a essas indagações deve ser dada dentro do contexto cultural e institucional do direito brasileiro. A restrição ao anonimato não é nova no Brasil nem é restrita ao inciso IV do art. $5^{\circ}$ da Constituição. A vedação já existia na Constituição de $1891^{17}$ e foi decisiva para consolidar o já mencionado paradigma da exigência de identificação na disciplina jurídica da liberdade de expressão no Brasil. $\mathrm{O}$ ápice da disciplina jurídica espelhada nesse paradigma esteve na chamada Lei de Imprensa (Lei 5.250/1967), aprovada pela mais recente ditadura civil-militar que governou o Brasil - e julgada inteiramente inconstitucional pelo Supremo Tribunal Federal em 2009, justamente por interferir excessivamente nas liberdades ligadas à livre expressão e informação ${ }^{18}$. $\mathrm{O}$ art. $7^{\circ}$ daquela lei, além de proibir o anonimato, autorizava o confisco sumário de qualquer impresso que não estampasse os nomes de seus autores e editores, e obrigava jornais, editoras, canais de televisão e estações de rádio a guardarem registros da identidade de todos os pseudônimos que veiculassem.

A disciplina jurídica das manifestações anonimizadas era relativamente simples até o advento da internet. A lógica era evitar vácuos de responsabilização por abusos no uso da liberdade de expressão e informação. Não por acaso, no art. $5^{\circ}$ da Constituição de 1988, o inciso seguinte àquele que veda o anonimato expressivo garante o direito

\footnotetext{
${ }^{17}$ Constituição da República dos Estados Unidos do Brasil (1891), art. 72: “\$12 - Em qualquer assunto é livre a manifestação de pensamento pela imprensa ou pela tribuna, sem dependência de censura, respondendo cada um pelos abusos que cometer nos casos e pela forma que a lei determinar. Não é permitido o anonimato".
}

${ }^{18}$ STF, ADPF 130, Tribunal Pleno, Rel. Min. Ayres Britto, j. 30 abr. 2009. 
de resposta e a "indenização por dano material, moral ou à imagem” (inc. V). Assim, em qualquer instância na qual a autoria de uma manifestação expressiva não fosse atribuível a alguém, deveria haver um terceiro que respondesse por ela: o sigilo constitucional garante ao jornalista o direito de não revelar a identidade de suas fontes, mas o profissional e seu jornal responderão eles próprios se publicarem reportagem caluniosa; a Lei de Direitos Autorais (Lei 9.610/1998) disciplina os direitos morais e patrimoniais sobre obras anônimas e pseudônimas, mas o editor sempre estará lá para responder por abusos nas publicações; autoridades podem receber informações anônimas pelos serviços de disque-denúncia e afins, mas investigações abusivas, com base exclusivamente nessas fontes, são nulas ${ }^{19}$ e autoridades que agiram de máfé poderão responder administrativa e até criminalmente. Nesses casos, ainda que não se saiba exatamente a identidade do autor da manifestação expressiva, há sempre alguém passível de responsabilização caso elas se relevem ilícitas. Desse modo, não haveria vácuo de responsabilização em caso de ato ilícito, ainda quando o real autor da manifestação não seja conhecido.

A internet veio a alterar esse arranjo simples e elegante. Em primeiro lugar, por uma particularidade da arquitetura jurídica da responsabilização pelo conteúdo postado: grandes portais e redes sociais são protegidos por uma imunidade quanto às manifestações expressivas de seus usuários. Essa regra é hoje positivada no Marco Civil da Internet (Lei 12.965/2014), segundo o qual o provedor de aplicações de internet não responde pelo conteúdo publicado por terceiros, mas apenas por descumprir ordem judicial para a remoção de conteúdo ilícito. ${ }^{20}$ Isso os torna, no ponto aqui analisado, fundamentalmente diferentes de editores de jornais, revistas, livros e programas de rádio e TV. Em segundo lugar, a internet é um território rico na diversidade de mecanismos de "anonimização" expressiva, embora essa “anonimização” seja, no mais das vezes ${ }^{21}$, meramente superficial ${ }^{22}$, ou não passe de

\footnotetext{
${ }^{19}$ STJ, HC 137.749, 6a Turma, Rel. Min. Maria Thereza de Assis Moura, j. 5 abr. 2011; e STJ, HC 159.159, 6a Turma, Rel. Min. Maria Thereza de Assis Moura, j. 5 abr. 2011.

${ }^{20}$ Lei 12.965/2014 (Marco Civil da Internet), art. 19: "Com o intuito de assegurar a liberdade de expressão e impedir a censura, o provedor de aplicações de internet somente poderá ser responsabilizado civilmente por danos decorrentes de conteúdo gerado por terceiros se, após ordem judicial específica, não tomar as providências para, no âmbito e nos limites técnicos do seu serviço e dentro do prazo assinalado, tornar indisponível o conteúdo apontado como infringente, ressalvadas as disposições legais em contrário." Segundo o art. 18 da mesma lei, os provedores de conexão estão igualmente acobertados por imunidade semelhante: "O provedor de conexão à internet não será responsabilizado civilmente por danos decorrentes de conteúdo gerado por terceiros.”

${ }^{21}$ Há autores para quem, dada a capacidade de tratamento de dados pessoais que necessariamente deixamos em nosso comportamento on-line, a real possibilidade de anonimato na internet é nula. Nesse sentido, v. Froomkin (2016).

${ }^{22}$ Como regra, o comportamento on-line de usuários de internet deixa rastros de informação variados, que podem ser usados para identificá-los mesmo quando eles se valem de técnicas que dificultam sua identificação (RODRIGUEZ, 2015, p. 16).
} 
mera expectativa ${ }^{23}$. De qualquer modo, ainda que apenas de modo superficial, o ciberespaço é pleno de alternativas à disposição de quem busca navegar, transmitir conteúdo e manifestar-se na rede sem ser ostensivamente identificado por seu nome, imagem, e-mail, telefone, localização etc. Finalmente, a internet tem uma capacidade única de produzir manifestações não mediadas de grande impacto. Antes dela, a emissão de opiniões com potencial de impacto pressupunha acesso a foros que restringiam a participação e impunham controles, como a imprensa profissional, as grandes editoras, as emissoras de rádio e os canais de televisão. Além de se colocarem como agentes juridicamente responsáveis por abusos expressivos, essas instituições, controladas por protocolos comportamentais mais rígidos e profissionais, acabavam por zelar por alguma liturgia na comunicação pública. Hoje, ao contrário, a fala livre e sem qualquer mediação encontra espaço em redes sociais, vídeos e comentários de portais, sempre com potencial de se disseminar instantaneamente, especialmente se seu conteúdo é jocoso, chocante, abjeto, indecoroso - isto é, quando destoa do padrão comedido que imperava na era da hegemonia das editorias profissionais de conteúdo.

A restrição ao anonimato é uma das alternativas que tem sido usada para enfrentar esse novo e desafiador cenário: se não há um jornalista ou editor passível de responsabilização, pois o art. 19 do Marco Civil da Internet exonera provedores de aplicação desse dever, então é preciso saber desde sempre quem é o autor da postagem. Caso contrário, poderia surgir um vácuo de responsabilidade que deixaria impune uma manifestação ilícita de um usuário que saiba ocultar eficazmente sua identidade on-line. Porém, a invocação excessiva da restrição ao anonimato traz risco de violação a formas legítimas de expressão de opiniões na internet, a exemplo dos três casos citados páginas atrás. Restringi-las não parece desejável, dada não apenas a inexistência de ilicitude em suas manifestações, como também o fato de que elas promovem valores constitucionalmente louváveis, e o fazem justamente com auxílio do anonimato. É preciso, portanto, encontrar um equilíbrio. As duas próximas seções serão dedicadas justamente a esses desafios: precisar uma concepção de anonimato, bem como de formas de reação judicial a manifestações anônimas, que encontre um bom termo entre a restrição constitucional à expressão anônima e o direito à livre expressão de ideias.

\footnotetext{
${ }^{23}$ Aplicativos com o Secret, que permitiam a postagem de comentários anônimos, retinham dados pessoais de seus usuários para poder atender a requisições judiciais, fato que era informado até mesmo nos termos de uso da aplicação. Por essa razão, segundo Carlos Affonso de Souza (2015), plataformas com essas características fornecem apenas um anonimato relativo, que se constitui em mera expectativa, e não a genuína possibilidade de um anonimato integral.
} 


\section{Duas concepções de anonimato}

O conceito de anonimato envolve algum grau de ocultação de identidade pelo uso de "técnicas de não identificabilidade" (MATTHEWS, 2010). Mas desse conceito amplo é possível tirar concepções mais detalhadas ${ }^{24}$. A depender da concepção que adotarmos para o conceito de anonimato, as diferenças jurídicas podem ser grandes. Nas seções seguintes, proponho duas possíveis concepções para o anonimato, para, em seguida, defender que a concepção adotada deve ser a mais restrita delas.

Por uma concepção restrita de anonimato, uma manifestação na internet será anônima se preencher duas condições: (i) se ela não trouxer, ostensivamente, a imagem, nome ou qualquer dado de identificação de seu autor, e (ii) se não houver um provedor de conexão ou aplicação que possa fornecer dados, mediante requisição do Poder Judiciário, que permitam a identificação desse autor.

Essa concepção é restrita porque limita o anonimato - e, portanto, a possibilidade de reação jurídica ao discurso anônimo - a situações bastante específicas, que respondem por uma parcela mínima do comportamento expressivo vulgarmente tido como anônimo na internet. Ela abrange apenas as manifestações de pessoas que intencionalmente buscam formas de resguardar seu comportamento on-line dos mecanismos usuais de identificabilidade, tais como ocultação de IPs, navegação por browsers que dificultam rastreamento e manifestação em fóruns que não guardam qualquer dado que identifique seus usuários, hospedados em jurisdições onde não há obrigação legal de fazê-lo.

Pela concepção restrita de anonimato, possivelmente nenhum dos três exemplos citados no início do artigo seria propriamente anônimo, ainda que a identidade de seus reais autores não seja ostensivamente veiculada junto com suas manifestações. $\mathrm{O}$ perfil de paródia Celso Barros Sincero, por exemplo, é uma fan page no Facebook, uma rede social com uma política rígida de identificação de seus usuários (CHEN, 2018). No Facebook, toda fan page é administrada por um perfil de usuário individual, de modo que uma simples requisição judicial à empresa bastaria para que dados pessoais do responsável fossem entregues à justiça, permitindo a identificação do administrador do perfil. No citado caso do portal Catho Online, o TJSP corretamente identificou essa circunstância e afastou qualquer restrição às postagens a título de anonimato: “o comentário questionado pelo embargante não é comprovadamente anônimo, [pois,]

\footnotetext{
${ }^{24}$ A distinção entre conceito e concepção é usual na filosofia jurídica contemporânea. "O contraste sobre conceito e concepção é um contraste sobre os níveis de abstração em que a interpretação de uma prática pode ser estudada” (DWORKIN, 1986, p. 71, tradução nossa). Conceito é o plateau sobre o qual refinamentos argumentativos ocorrem, ao passo que concepções dos conceitos são os níveis em que controvérsias latentes ao conceito são trabalhadas.
} 
para comentar, as pessoas devem possuir cadastro no sítio" ${ }^{25}$. Mesmo no caso de criação de uma conta pseudonimizada em um provedor de aplicação como o YouTube, com um e-mail igualmente pseudonimizado para contato, o responsável ainda pode ser identificado por meio de seus registros de conexão e acesso a provedores de aplicação, como previsto no Marco Civil da Internet. Em outras palavras, os autores das postagens não estão identificados, mas são identificáveis, e o que é identificável não é anônimo em uma concepção restrita de anonimato.

Embora sem articulá-la explicitamente, alguns poucos acórdãos do TJSP estudados na pesquisa que deu origem a este artigo revelaram entendimentos compatíveis com essa concepção restrita de anonimato. Foram os casos de julgamentos relativos a direitos autorais por fotografias usadas sem autorização dos respectivos fotógrafos. Os réus nessas ações alegavam que as imagens seriam de domínio público, pois estavam disponíveis em páginas da internet sem marca de identificação autoral. Portanto, diziam eles, as imagens deveriam ser tratadas com obras anônimas, passíveis de utilização sem prévia autorização ou necessidade de pagamento de direitos autorais. Em alguns casos, o TJSP recusou esse argumento sob a justificativa de que a identidade do titular de direitos autorais poderia ser descoberta por meio de diligências, tal como uma busca de imagem. Logo, não haveria anonimato se a autoria da obra, embora não ostensivamente identificada, fosse identificável mediante diligências razoavelmente exigíveis de um interessado de boa-fé. Nesse sentido, confira-se a seguinte passagem de um dos acórdãos do tribunal paulista:

a autoria da obra fotográfica poderia ser constatada por outros meios, não se tratando de obra de autor desconhecido, submetida ao regime das obras pertencentes ao domínio público. (...) [R] estava possibilitada aos apelados a realização de "pesquisa por imagem" através de ferramenta fornecida pelo próprio site de buscas na Internet (fls. 113/114), com vistas a se aferir a autoria da obra fotográfica utilizada. ${ }^{26}$

Ao lado dessa concepção restrita, é possível pensarmos em uma concepção ampla de anonimato. Por uma concepção ampla, uma manifestação será anônima e, portanto, sujeita a algum grau de intervenção jurídica, quando não trouxer, ostensivamente e desde o princípio, a imagem, nome ou qualquer dado de identificação de seu autor. Por essa concepção, todos os três exemplos da primeira seção deste texto - o perfil críticosatírico Celso Barros Sincero, os comentários pseudonimizados em portal de RH e a denúncia anônima de crime - seriam anônimos e, portanto, estariam em potencial violação à restrição constitucional do art. $5^{\circ}$, inc. IV.

\footnotetext{
${ }^{25}$ TJSP, ED 2077958-72.2016.8.26.0000, 21 a Câmara de Direito Privado, Rel. Des. Virgilio de Oliveira Jr., j. 31 jul. 2017. 
A favor dessa concepção, somente se pode dizer que ela respeita o conteúdo semântico possível de anonimato: a não identificação ostensiva do autor de uma manifestação é, afinal, um certo grau de ocultação de sua identidade. Tirando isso, tudo nela perece exagerado e imprestável para fundamentar a compreensão da restrição a uma liberdade fundamental constitucionalmente assegurada. Primeiro, porque ela exige um grau de identificabilidade excessivamente alto - sem paralelo, inclusive, fora do contexto da internet. Por essa concepção, p. ex., pseudônimos literários, que são prática comum no mercado editorial e objeto de disciplina específica na Lei de Direitos Autorais ${ }^{27}$, seriam anonimato e estariam em potencial violação à Constituição. Pela concepção ampla, a obra pseudonimizada de Elena Ferrante seria inconstitucional, pois ninguém sabe, ao certo, a verdadeira identidade da autora ${ }^{28}$.

A despeito de estar na contramão de nossas práticas comunicativas fora do espaço da internet, essa concepção é compatível com a apreciação do anonimato em muitas das decisões judiciais encontradas na pesquisa que deu origem a este artigo. Nessas decisões, a simples circunstância de uma manifestação na internet não vir acompanhada da identidade real de seu autor implicava classificá-la como anônima, levando a variadas formas de intervenção sobre as publicações, ainda quando o teor da afirmação não fosse ilícito. Assim, por exemplo, o perfil satírico Clovis Fake Bronza foi removido do Facebook a pedido da pessoa satirizada, sob fundamento da proibição ao anonimato ${ }^{29}$, muito embora os dados reais do administrador do perfil estivessem à disposição da justiça mediante simples requerimento, nos termos do Marco Civil da Internet, em caso de prática de ato ilícito. Nesse caso, ao contrário do observado no caso do portal Catho Online, não bastou que o autor da manifestação fosse identificável; exigiu-se que ele estivesse, de plano, identificado.

\section{Três intensidades de intervenção}

A escolha de uma entre duas concepções possíveis de anonimato é apenas o primeiro passo para a interpretação da restrição constitucional à liberdade constitucional de manifestação de pensamento. Qualquer quer seja a concepção

\footnotetext{
${ }^{27}$ Cf. Lei 9.610/1998, arts. 5, 12 e 40, entre outros.

${ }^{28}$ Além de Ferrante, Virgilio Afonso da Silva lembra também o clássico espanhol Lazarillo de Tormes, de autoria desconhecida, como obra potencialmente inconstitucional caso a restrição ao anonimato fosse aplicada de modo excessivamente amplo (SILVA, V., 2021, p. 171).

29 “O autor pretende a obtenção dos dados do responsável pela criação do perfil 'ClovisFakeBronza', bem como de todos os perfis acessados com o mesmo IP. [...] Há de se ressaltar que o respeito ao mencionado dispositivo independe da verificação do conteúdo ofensivo das postagens, mas se refere unicamente ao fato de se vedar, constitucionalmente, o anonimato" (TJSP, AC 000650739.2013.8.26.0222, 26a Câmara de Direito Privado, Rel. Des. Antonio Nascimento, j. 2 jul. 2017).
} 
escolhida, há uma questão independente que é a de saber (i) quando e (ii) como deve se dar a reação jurídica ao anonimato. Essa reação pode se dar por diferentes intensidades de intervenção. Nos julgados estudados na pesquisa, os tipos de respostas judiciais à constatação de exercício anonimizado de expressão puderam ser agrupados em três categorias, que representam níveis mais ou menos intensos de intervenção sobre as ideias veiculadas na internet.

A intervenção máxima pode ser assim enunciada: havendo manifestação na internet que se possa considerar anônima, qualquer que seja a concepção de anonimato adotada, tal manifestação deve ser removida da aplicação que a hospeda e seu autor deve ser identificado, independentemente do caráter ilícito de qualquer manifestação sua.

Essa foi a postura do TJSP no já mencionado caso dos perfis satíricos Celso Barros Irônico e Clovis Fake Bronza. Nesses casos, o tribunal decidiu que o anonimato, mesmo que superficial (i.e., a falta de identificação ostensiva dos administradores do perfil), justificava, por si só, a remoção completa dos perfis, ainda que eles não tivessem postado qualquer conteúdo ilícito. Para os adeptos da intervenção máxima, a atuação judicial se justifica porque a ilicitude em questão independe do conteúdo da manifestação: ela decorre da simples forma - não ostensivamente identificada - do comentário. Vale notar que, nos exemplos mencionados, a intervenção máxima veio associada a uma concepção ampliada de anonimato. Isso equivale a sustentar que um perfil de paródia em rede social não tem o direito de existir, a não ser que seu autor seja ostensivamente identificado de alguma maneira na página.

Além da intervenção máxima, é possível pensar em uma intensidade média de intervenção, que pode ser assim enunciada: havendo manifestação na internet que se possa considerar anônima, qualquer que seja a concepção de anonimato adotada, o autor de tal manifestação deve sempre ser identificado, independentemente do caráter ilícito da manifestação; a manifestação, porém, somente deve ser removida da aplicação que a hospeda se houver ilicitude em seu conteúdo.

Essa reação foi muito frequente nos acórdãos do TJSP estudados na pesquisa que originou este artigo. Apenas como exemplo, cite-se o agravo de instrumento no qual a Igreja Universal do Reino de Deus, em tutela de urgência, buscava (i) identificar os autores e (ii) remover o conteúdo da página Eu não sou a Universal! de uma rede social $^{30}$. Na decisão, o TJSP reconheceu que as publicações, embora críticas à atuação daquela Igreja, não poderiam ser removidas em medida cautelar, sob pena de "afronta o direito à livre circulação de notícias e opiniões”. Contudo, determinou a identificação 
dos usuários responsáveis pelo perfil, dado o "direito do autor de conhecer a identidade de seu interlocutor”. Na intervenção média, portanto, a ilegalidade pela forma (i.e., independentemente do conteúdo) não é tamanha a ponto de justificar, por si, a remoção do conteúdo, mas é bastante para fazer o Judiciário mover-se para identificar compulsoriamente o autor da manifestação, requisitando dados pessoais aos provedores de aplicação e conexão. A intervenção média parte do pressuposto de que qualquer pessoa (ou empresa, organização religiosa etc.) tem um direito subjetivo de conhecer a real identidade de qualquer pessoa que fale a seu respeito na internet, independentemente do caráter lícito ou ilícito da manifestação.

Finalmente, é possível pensar em uma intervenção de intensidade mínima para as situações de anonimato na internet. Ela pode ser assim enunciada: havendo manifestação na internet que se possa considerar anônima, qualquer que seja a concepção de anonimato adotada, tanto a identificação do autor quanto a remoção de conteúdo dependerão, sempre, do conteúdo prima facie ilícito da manifestação.

A opção pela intervenção mínima recusa qualquer tipo de intervenção sobre uma manifestação de opinião, até mesmo para a mera identificação de seu autor, se o conteúdo dessa manifestação não for ilícito. Portanto, ela rejeita qualquer interferência estatal nas esferas de expressão (pois não admite remoção da manifestação) ou privacidade (pois não admite requisição de dados pessoais de identificação) pela simples forma anônima da manifestação. A intervenção mínima condiciona qualquer forma de intervenção a uma ilegalidade substantiva à primeira vista, tais como, manifestações caluniosas, difamatórias, racistas, antissemíticas etc.

Um exemplo de intervenção mínima aparece no Agravo de Instrumento 2077958-72.2016.8.26.0000 ${ }^{31}$. Trata-se de uma das ações envolvendo o já citado portal de recursos humanos Catho Online. Nesse caso específico, a empresa Brother International Corporation do Brasil Ltda. buscava remoção de comentários negativos a respeito de seu ambiente de trabalho, feitos nos fóruns daquele portal - por exemplo, "só aceite se estiver muito desesperado!". Na ocasião, o TJSP entendeu que o comentário não seria difamatório, mas apenas expressivo da opinião subjetiva (e lícita) de um ex-empregado sobre a empresa ${ }^{32}$. Em embargos de declaração no mesmo agravo de instrumento, a empresa alegou que os comentários, ainda que não fossem

\footnotetext{
${ }^{31}$ TJSP, ED no AI 2077958-72.2016.8.26.0000, 21 a Câmara de Direito Privado, Rel. Des. Virgilio de Oliveira Junior, j. 9 out. 2017.

32 "Como se verifica do próprio teor dos comentários, não há qualquer intenção difamatória nas informações e comentários apresentados. Verifica-se, inclusive, a apresentação de qualidades da empresa, fazendo-se o contraponto com as deficiências verificadas pelos autores. Observa-se que os comentários dos autores refletem tão somente a opinião pessoal deles. E, opinião, cada um possui a sua, sendo perfeitamente permitida a sua manifestação" (TJSP, AI 2077958-72.2016.8.26.0000, 21 ${ }^{\text {a }}$ Câmara de Direito Privado, Rel. Des. Virgilio de Oliveira Junior, j. 13 mar. 2017).
} 
ilícitos, eram anônimos, e que isso bastava para caracterizar violação à restrição constitucional ao anonimato. Essa segunda investida da empresa foi rechaçada sob a justificativa de que as críticas não tinham conteúdo difamatório, e a simples circunstância de que tivessem sido postados sob um pseudônimo não justificava qualquer intervenção judicial sobre a manifestação:

[...] os comentários questionados pelo autor, a princípio, não se mostram anônimos. [...] o comentário foi feito no sítio da empresa Catho, que é empresa "do ramo de integração entre futuros empregados e empregadores, lidando, pois, com a oferta de vagas de empregos”. Assim, tanto os empregadores como os pretendentes a uma vaga de emprego possuem cadastro no sítio. Se o nome não é explícito no destaque apresentado pelo autor, não se pode dizer com certeza, que as afirmações são anônimas. ${ }^{33}$

Esse caso ilustra bem o atrativo da intervenção mínima do anonimato. Caso o tribunal reconhecesse, como ocorreu nos casos de intervenção média, que a empresa tinha um direito fundamental a conhecer a identidade de seus interlocutores, essa revelação poderia prejudicá-los em processos seletivos futuros. Em alguns casos, não é possível sequer usar o problemático bordão segundo o qual "quem não deve não teme”. No caso mencionado da Igreja Universal do Reino de Deus, os autores de críticas lícitas que sejam compulsoriamente identificados por ordem judicial poderão ser expostos a retaliações através do abuso de direito de ação, por meio do ajuizamento pulverizado de demandas em juizados de pequenas causas em todo o território nacional - prática recentemente adotada por membros da mesma entidade para retaliar um escritor que a criticou no Twitter $^{34}$.

A opção pela intervenção mínima protege autores de manifestações lícitas contra retaliações que, embora desamparadas de fundamentação legal, podem implicar ônus financeiros e emocionais para seu enfrentamento ${ }^{35}$. A intervenção mínima chama a atenção para o valor que há em restringir a atuação interventiva do Poder Judiciário aos casos em que a doutrina e a jurisprudência reconhecem o conteúdo como abusivo (caluniador, difamatório, racista, de ódio etc.) na manifestação combatida, admitindo que a identidade de seu autor permaneça desconhecida, embora ela seja - caso necessário para punição de um ilícito - conhecível.

\footnotetext{
${ }^{33}$ TJSP, AI 2077958-72.2016.8.26.0000, 21 a Câmara de Direito Privado, Rel. Des. Virgilio de Oliveira Junior, j. 13 mar. 2017.

34 “[João Paulo Cuenca] é alvo de uma ampla ofensiva judicial devido a um tuíte que publicou em junho. Mais de cem pastores da Igreja Universal, uma das denominações evangélicas mais poderosas do Brasil, exigem nos tribunais indenizações por causa desta frase: 'O brasileiro só será livre quando o último Bolsonaro for enforcado nas tripas do último pastor da Igreja Universal,'” (GORTÁZAR, 2020).

${ }^{35}$ A prática de intimidação via litigância massiva é conhecida como SLAPP (Strategic Litigation Against Public Participation), acrônimo cunhado por George Pring e Penelope Canan (1996).
} 


\section{Como devemos interpretar a restrição constitucional ao anonimato no ambiente de internet?}

Se temos duas concepções possíveis de anonimato e três intensidades possíveis de intervenção, como devemos interpretar a restrição constitucional ao anonimato, em busca do equilíbrio entre, de um lado, o direito à livre expressão de pensamento e, de outro, o direito de reparação das vítimas de abusos dessa liberdade?

Um primeiro critério para a escolha entre as interpretações possíveis é avaliar o quanto elas se ajustam às práticas consolidadas sobre manifestações sem identificação ostensiva no Brasil. Por esse critério, a concepção ampla de anonimato deve ser descartada. Como já foi dito, o cerne da concepção ampla é considerar como anônima e, portanto, constitucionalmente proibida qualquer forma de manifestação que não venha imediatamente acompanhada da real identidade de seu autor (ainda que ela seja passível de ser descoberta com pequeno esforço, se necessário for). Em suma, a concepção ampla de anonimato trata qualquer manifestação sem indicação ostensiva de autoria como ilícita - e, portanto, passível de alguma intervenção judicial - por sua própria forma, independentemente de o teor da manifestação ser lícito ou ilícito. Mas uma concepção tão ampla de anonimato, para fins de restrição expressiva, não se amolda às práticas jurídicas estabelecidas para o direito de expressão em geral.

Fora da internet, aceitamos manifestações pseudonimizadas e fantasias de protesto, como também reconhecemos que pessoas têm o direito de ocultar sua identidade expressiva para fins de se proteger contra retaliações e violência, como no caso de denúncias ou delações anônimas, previstas em lei e aceitas pelos tribunais (SILVA, V., 2021, p. 170).

A concepção ampla de anonimato também ignora o fato de que a publicação não identificada (anonimizada ou pseudonimizada) é prevista tanto em lei, como ocorre com a Lei de Direitos Autorais, quanto na própria Constituição, que admite sigilo quanto à identidade da fonte jornalística. Analogamente ao que ocorre com a publicação de um livro pseudonimizado, caso haja necessidade, a pessoa responsável por uma manifestação ilícita não identificada será provavelmente identificável por meio de informações que provedores de aplicação e conexão são capazes de fornecer ao Poder Judiciário.

Mais ainda, a concepção ampla também ignora que um suposto direito de conhecer a real identidade de quem se manifesta não existe: a editora ou os empresários de uma obra publicada sob pseudônimo têm o direito de não informar a real identidade da escritora ou escritor a um leitor que se julgue no (suposto) direito subjetivo de saber quem ele verdadeiramente está lendo. 
Por fim, a concepção ampla ignora que a própria estratégia de anonimização pode fazer parte do arsenal expressivo da comunicação. Esse é o caso de muitas fantasias de super heróis em protestos, ou de um avatar chamativo em rede social, que têm o condão de impulsionar o alcance de uma manifestação perfeitamente lícita. Essa era provavelmente a intenção do perfil Celso Barros Sincero. Considerando-se, ademais, que o direito à livre expressão de pensamento tem sido tratado com grande peso pelo Supremo Tribunal Federal ${ }^{36}$, a interpretação da restrição que o anonimato lhe impõe, por coerência normativa ${ }^{37}$, deve tender para a minimização, de modo a diminuir o impacto negativo sobre aquela liberdade.

Superada a questão da concepção de anonimato, que deve ser restrita, resta decidir pela intensidade da intervenção que responderá ao anonimato, quando ele ocorrer. Aqui, as opções são, relembrando: (i) uma intensidade máxima, que trata o anonimato como uma ilicitude pela mera forma da manifestação e recomenda tanto a identificação compulsória do autor da manifestação quanto a remoção da manifestação anônima (ou mesmo de todo o perfil, blog etc.); (ii) uma intensidade média, que não determina a remoção da manifestação, a não ser que seu conteúdo seja ilícito, mas ainda assim aceita a identificação compulsória do autor da manifestação, porque terceiros teriam um suposto direito de conhecer a real identidade de quem se manifeste; e (iii) uma intensidade mínima de intervenção, que é pautada pelo caráter substantivamente ilícito da manifestação e só admite qualquer intervenção, ainda que a simples identificação compulsória, se houver conteúdo ilegal (calúnias, difamações, racismo etc.) a ser enfrentado.

Também aqui, a preferência deve ser dada ao direito de livre expressão, optando-se pela intervenção de intensidade mínima. O Poder Judiciário somente deve agir nos casos em que o teor de uma manifestação for substantivamente ilícito e extrapolar os limites da expressão legítima. Fora dessas hipóteses, deve manterse inerte, não perseguindo sequer a identificação do autor da manifestação. Nesse sentido, o próprio Marco Civil da Internet, que condiciona o fornecimento de dados pessoais capazes de identificação dos usuários de internet à existência de

\footnotetext{
36 "O Poder Legislativo e os [...] tribunais inferiores tendem a impor ou aceitar mais restrições à liberdade de expressão do que o Supremo Tribunal Federal. Enquanto os primeiros em muitos casos tendem a dar preferência a outros direitos como honra, privacidade, imagem ou propriedade, a jurisprudência do STF é mais favorável à liberdade de expressão” (SILVA, V., 2021, p. 167). Para uma detalhada exposição de recentes posicionamentos do STF sobre liberdade de expressão e suas possíveis restrições, v. $\operatorname{Ramos}(2017$, p. 167 et seq.).

${ }^{37}$ Coerência normativa exige que diferentes proposições normativas sobre os mesmos temas se liguem a valores comuns que sejam atendidos por essas normas. Nesse sentido, MacCormick, 2005, p. 191 et seq.
} 
"fundados indícios da ocorrência do ilícito", ${ }^{38}$ descarta a opção tanto pela intervenção máxima quanto pela intervenção média: se a identificação compulsória pressupõe ocorrência de ilícito, é evidente que esse ilícito não pode ser constituído pelo próprio anonimato, que leva à necessidade de identificação. O ilícito daquela lei, para fins de requisição de dados visando à identificação de usuários de internet, só pode se referir a situações de violação ilícita à intimidade, à vida privada, à honra e à imagem de terceiros ${ }^{39} \mathrm{e}^{40}$. Tal ilicitude não ocorre nos casos de emissão de opinião lícita, ainda que de conteúdo crítico, ácido, duro ou debochado. Os exemplos da abertura deste artigo, i.e., a manutenção de perfil de paródia de uma personalidade pública, a crítica a um antigo empregador em um fórum do portal Catho Online, ou a postagem de vídeo com flagrante de crime cometido por agente público no YouTube, recaem todos, em princípio, no terreno da licitude, não havendo razão para considerá-los ilegais pela simples ausência de identificação ostensiva de seus autores, nem justificativa para qualquer ação do Judiciário para identificá-los contra sua (presumida) vontade. Posição análoga encontra eco em uma leitura puramente normativa do problema, sem relação com o direito positivo brasileiro. Como aponta Skopek (2015), medidas de identificação têm um grau inerente de invasividade e pressupõem justa causa, consistente ao menos na suspeita de conduta ilícita pela pessoa identificada.

\section{Conclusão}

Como visto no início deste texto, a reprovação ao anonimato é comumente justificada por sua associação à evasão de responsabilidade por abusos no exercício da liberdade de expressão. Assim, manifestar-se anonimamente seria artimanha de quem busca escapar das consequências de suas ações e palavras ilícitas e abusivas, não

\footnotetext{
${ }^{38}$ Cf. Lei 12.965/2014 (Marco Civil da Internet), com destaques meus. Art. 10, $\$ 1^{\circ}$ : “O provedor responsável pela guarda somente será obrigado a disponibilizar os [registros de conexão e de acesso a aplicações de internet], de forma autônoma ou associados a dados pessoais ou a outras informações que possam contribuir para a identificação do usuário ou do terminal, mediante ordem judicial, na forma do disposto [nos arts. 22 e 23], respeitado o disposto no art. 7o". E também o art. 22 da mesma lei: "A parte interessada poderá, com o propósito de formar conjunto probatório em processo judicial cível ou penal, em caráter incidental ou autônomo, requerer ao juiz que ordene ao responsável pela guarda o fornecimento de registros de conexão ou de registros de acesso a aplicações de internet". "Parágrafo único. Sem prejuízo dos demais requisitos legais, o requerimento deverá conter, sob pena de inadmissibilidade: I - fundados indícios da ocorrência do ilícito [...]”.

${ }^{39}$ Nesse sentido, o art. 10, caput, da mesma lei estabelece que "[...] a guarda e a disponibilização dos registros de conexão e de acesso a aplicações de internet de que trata esta Lei, bem como de dados pessoais e do conteúdo de comunicações privadas, devem atender à preservação da intimidade, da vida privada, da honra e da imagem das partes direta ou indiretamente envolvidas" (grifo nosso).

${ }^{40}$ Vale destacar que a jurisprudência do Superior Tribunal de Justiça tem caminhado para uma leitura rígida do art. 22 do Marco Civil da Internet, exigindo a demonstração dos requisitos de seus incisos para autorizar a requisição de dados pessoais dos usuários, e limitando os dados requisitáveis àqueles previstos na lei. Nesse sentido, v. STJ, RESP 1.829.821, 3a Turma, Rel. Min. Nancy Andrighi, j. 25 ago. 2020.
} 
estando disposto a arcar com a responsabilidade por aquilo que diz. Sob essa luz, a manifestação de pensamento anônima seria essencialmente indigna e não merecedora de proteção jurídica.

Os debates doutrinários especificamente relacionados ao anonimato no ambiente da internet, bem como a variedade de situações concretas identificadas nos julgados da pesquisa jurisprudencial que deu origem a este texto, sugerem que tal visão é demasiadamente estreita. Ela não captura a multiplicidade de objetivos legítimos que a ocultação de identidade ostensiva na internet é capaz de abarcar, e ignora a maximização que ela pode promover em relação a direitos fundamentais como a liberdade de expressão e a privacidade.

A interpretação da vedação constitucional ao anonimato deve preferir uma concepção restrita desse conceito, que exclua situações de anonimato meramente superficial, fraco ou aparente. Além disso, a resposta jurídica a situações de ausência de identificação do autor de uma manifestação expressiva deve privilegiar a intervenção mínima (intervenção de baixa intensidade): qualquer esforço de identificação do autor de uma manifestação pressupõe a existência de ilicitude no ato expressivo, e sua responsabilização demanda a identificação de seu autor. Tal ilicitude não se confunde com a própria ausência de identificação (ilicitude pela forma), mas se limita aos casos em que o teor da manifestação seja substantivamente ilícito, como ocorre nas calúnias, ameaças, manifestações racistas e discriminatórias em geral.

Se a vedação ao anonimato é instrumental ao direito de resposta e indenização a agravos que impliquem dano material, moral ou à imagem, é cabível pensar que o anonimato expressivo seja admissível quando não serve de escudo à prática de atos ilícitos, mas, ao contrário, favorece o legítimo exercício do direito à livre expressão. Na medida em que a própria Constituição protege o anonimato das fontes jornalísticas, não faz sentido interpretar a restrição do inciso IV do art. $5^{\circ}$ como um impedimento constitucional absoluto e incontornável contra qualquer manifestação que não esteja acompanhada da taxativa identificação de seu autor.

Se a questão se restringe à possibilidade de responsabilização pela prática de atos ilícitos, o debate sobre a restrição ao anonimato em manifestações na internet pressupõe, justamente, a prática de um ato ilícito. Na linha do que estabelece o Marco Civil da Internet, em seu art. 22, qualquer iniciativa visando à identificação de usuários de internet pressupõe fundados indícios da ocorrência de um ilícito - um requisito que deve ser rigorosamente apreciado pelo Judiciário em qualquer requerimento para a obtenção de dados pessoais sob guarda de provedores de aplicação e conexão. 
Nesse sentido, não existe um direito subjetivo de qualquer pessoa em conhecer a identidade real de qualquer um que se manifeste a seu respeito. Pessoas citadas em reportagens jornalísticas por fontes ouvidas em condição de anonimato, ou implicadas em denúncias anônimas às autoridades policiais, não têm um direito constitucional, fundado na restrição ao anonimato, de conhecer a identidade dos informantes anônimos. O direito de conhecer a identidade de seu interlocutor restringe-se às situações em que tal identificação seja necessária para a responsabilização desse interlocutor por ato ilícito, como ocorre em casos de calúnia e outras violações à imagem e à honra. A restrição constitucional ao anonimato ampara medidas para a identificação compulsória de cidadãos apenas nessas situações pontuais, e não em caráter geral e irrestrito.

Não havendo ato ilícito na manifestação, técnicas de anonimização são não apenas lícitas, como podem até mesmo maximizar a livre manifestação garantida pela Constituição, a exemplo do que ocorre nos mencionados perfis satíricos, cujo potencial de impacto é favorecido pela roupagem humorística do avatar. Em sentido contrário, o paradigma da identificação compulsória sujeita autores de críticas legítimas, feitas contra agentes públicos e privados poderosos, a possíveis constrangimentos custosos, como ações judiciais abusivas, que eles não têm o dever de suportar. Tais medidas podem inibir o exercício de seu direito de criticar e denunciar ilegalidades das quais tenham conhecimento - justamente o oposto do que o paradigma da identificação compulsória promete entregar. Nessas situações, a obrigação de identificação compulsória só ajuda quem deseja esquivarse de responsabilização na esfera pública. Não há razões convincentes para que tal interpretação seja abrigada no texto da Constituição.

Técnicas de anonimização na internet ainda otimizam outros direitos fundamentais, a exemplo do direito à privacidade. Em um mundo no qual há crescente receio quanto à vigilância intrusiva de cidadãos, mesmo aqueles sobre os quais não há qualquer suspeita de comportamento ilícito, é justificado que busquemos minimizar a exposição de nossa identidade e de nossos dados pessoais na internet. $\mathrm{O}$ direito à privacidade deve compreender uma expectativa razoável de circulação, tanto no ciberespaço como no mundo físico, sem que sejamos obrigados à identificação ostensiva. A identificação compulsória e universal de cidadãos, não só de usuários de internet como de qualquer frequentador de espaços públicos (por câmeras de vigilância, por exemplo), não pode ser condição para nossa interação social, nem em modo presencial, nem em modo virtual. 


\section{Referências}

BONOTTO, Ana Carolina Garcia. O anonimato na ordem jurídico-constitucional brasileira e suas implicações na internet. 2017. Dissertação (Mestrado em Direito) Pontifícia Universidade Católica do Rio Grande do Sul, Escola de Direito, Porto Alegre, 2017. Disponível em: https://tede2.pucrs.br/tede2/bitstream/tede/9094/2/Ana_Cristina_Bonotto.pdf. Acesso em: 16 abr. 2021.

CHEN, Shun-Ling. What's in a name: Facebook's real name policy and user privacy. Kansas Journal of Law \& Public Policy, v. 28, n. 1, p. 146-172, 2018.

DWORKIN, Ronald. Law's empire. Cambridge (MA): Belknap; Harvard, 1986.

DWORKIN, Ronald. The model of rules I. The University of Chicago Law Review, v. 35, n. 14, p. 14-46, 1967.

FACEBOOK. Por que é muito melhor criar uma Página no Facebook para seu negócio. 5 ago. 2014. Disponível em: https://www.facebook.com/business/news/BR-Por-que-e-muitomelhor-criar-uma-Pagina-no-Facebook-para-seu-negocio. Acesso em: 30 nov. 2020.

FROOMKIN, Michael. Lessons learned too well: anonymity in a time of surveillance. Arizona Law Review, n. 59, p. 95-159, 2016.

GORTÁZAR, Naila Galarraga. A cruzada judicial de 111 pastores da Igreja Universal contra um escritor por um tuíte. El País, 18 out. 2020. Disponível em: https://brasil.elpais. com/cultura/2020-10-18/a-cruzada-judicial-de-111-pastores-evangelicos-contra-um-escritorbrasileiro-por-um-tuite.html. Acesso em: 3 dez. 2020.

[HOUAISS] Instituto Antônio Houaiss de Lexicografia. Pequeno Dicionário Houaiss de Língua Portuguesa. São Paulo: Moderna, 2015. Dir. Antônio Houaiss, Mauro de Salles Villar, Francisco Manoel de Mello Franco.

LESSIG, Lawrence. Code: version 2.0. New York: Basic Books, 2006.

MACCORMICK, Neil. Rhetoric and the rule of law: a theory of legal reasoning. Oxford: Oxford University Press, 2005.

MACHADO, Diego; DONEDA, Danilo. Direito ao anonimato na internet: fundamentos e contornos dogmáticos de sua proteção no Direito Brasileiro. Revista de Direito Civil Contemporâneo, v. 7, n. 23, p. 95-140, abr./jun. 2020.

MASSA, Felipe G. Guardians of the internet: building and sustaining the anonymous online community. Organization Studies, v. 38, n. 7, p. 1-30, 2016.

MATTHEWS, Steve. Anonymity and the social self. American Philosophical Quarterly, v. 47, n. 4, p. 351-63, 2010. 
MONTEIRO, Artur Pericles Lima. Online anonymity in Brazil: identification and the dignity in wearing a mask. 2017. Dissertação (Mestrado em Direito do Estado) - Faculdade de Direito, Universidade de São Paulo, São Paulo, 2017.

MORAES, Alexandre. Direito Constitucional. 36. ed. Río de Janeiro: Gen/Atlas, 2020.

PRING, George; CANAN, Penelope. SLAPPs: Getting sued for speaking out. Philadelphia: Temple University Press, 1996.

RAMOS, André de Carvalho. Curso de Direitos Humanos. 4. ed. São Paulo: Saraiva, 2017.

RODRIGUEZ, Katitza. Anonymity and encryption: comments submitted to the United Nations Special Rapporteur on the Promotion and Protection of the Right to Freedom of Opinion and Expression. Electronic Frontier Fountation. 10 fev. 2015. Disponível em: https://www.ohchr. org/Documents/Issues/Opinion/Communications/EFF.pdf. Acesso em: 7 abr. 2020.

ROGAL, Laura. Anonymity in Social Media. Arizona Law Review, v. 7, n. 61, p. 61-77, 2013.

SILVA, José Afonso da. Curso de Direito Constitucional positivo. 35. ed. São Paulo: Malheiros, 2012.

SILVA, Virgilio Afonso. Direito constitucional brasileiro. 1. ed. São Paulo: Edusp, 2021.

SKOPEK, Jeffrey M. Reasonable Expectations of Anonymity. Virginia Law Review, v. 101, n. 3, p. 691-762, 2015.

SOUZA, Carlos Affonso Pereira de. As cinco faces da proteção à liberdade de expressão no marco civil da internet. In: LUCCA, N. de; SIMÃO FILHO, A.; LIMA, C. R. P. de (coord.). Direito \& Internet III: marco civil da internet Lei no 12965/2014. São Paulo: Quartier Latin, 2015. t. 2, p. 377-408.

\section{Jurisprudência citada}

BRASIL. Superior Tribunal de Justiça (6. Turma). Habeas Corpus 137.349/SP. Relatora: Min. Maria Thereza de Assis Moura, 05 de abril de 2011. Disponível em: https://processo.stj.jus. $\mathrm{br} / \mathrm{processo} / \mathrm{revista} / \mathrm{documento} / \mathrm{mediado} /$ ?componente $=$ ITA\&sequencial=1002984\&num_ registro $=200901010385 \&$ data $=20110530 \&$ peticao_numero $=-1 \&$ formato $=$ PDF. Acesso em: 3 jun. 2021.

BRASIL. Superior Tribunal de Justiça (6. Turma). Habeas Corpus 159.159/SP. Relatora: Min. Maria Thereza de Assis Moura, 05 de abril de 2011. Disponível em: https://processo.stj.jus. $\mathrm{br} / \mathrm{processo} / \mathrm{revista} / \mathrm{documento} / \mathrm{mediado} /$ ?componente=ITA\&sequencial=1003299\&num_ registro $=201000040393 \&$ data $=20110530 \&$ peticao_numero $=-1 \&$ formato $=$ PDF. Acesso em: 3 jun. 2021.

BRASIL. Superior Tribunal de Justiça (3. Turma). Recurso Especial 1.829.821/SP. Relatora: Min. Nancy Andrighi, 25 de agosto de 2020. Disponível em: https://processo.stj.jus.br/ processo/revista/documento/mediado/?componente $=$ ITA\&sequencial $=1974094 \&$ num $_{-}$ 
registro $=201901493754 \&$ data $=20200831 \&$ peticao_numero $=-1 \&$ formato=PDF. Acesso em: 3 jun. 2021.

BRASIL. Supremo Tribunal Federal (Tribunal Pleno). Arguição de Descumprimento de Preceito Fundamental 130/DF. Relator: Min. Ayres Britto, 30 de abril de 2009. Disponível em: https://stf.jus.br/portal/inteiroTeor/obterInteiroTeor.asp? numero=130\&classe=ADPF. Acesso em: 27 maio 2021.

BRASIL. Tribunal de Justiça do Estado de São Paulo (7. Câmara de Direito Privado). Agravo de Instrumento 0366898-73.2010.8.26.0000. Relator: Des. LuizAntonio Costa, 17 de novembrode 2010. Disponível em: https://esaj.tjsp.jus.br/cjsg/getArquivo.do? cdAcordao=4805786\&cdForo=0. Acesso em: 28 maio 2021.

BRASIL. Tribunal de Justiça do Estado de São Paulo (21. Câmara de Direito Privado). Agravo de Instrumento 2077958-72.2016.8.26.0000. Relator: Des. Virgilio de Oliveira Junior, 13 de março de 2017. Disponível em: https://esaj.tjsp.jus.br/cjsg/getArquivo. do? cdAcordao=10313538\&cdForo=0. Acesso em: 27 maio 2021.

BRASIL. Tribunal de Justiça do Estado de São Paulo (3. Câmara de Direito Privado). Agravo de Instrumento 2163007-13.2018.8.26.0000. Relator: Des. Donegá Morandini, 28 de setembro de 2018. Disponível em: https://esaj.tjsp.jus.br/cjsg/getArquivo.do?cdAcordao=11861946\&cdForo=0. Acesso em: 26 maio 2021.

BRASIL. Tribunal de Justiça do Estado de São Paulo (6. Câmara de Direito Privado). Agravo de Instrumento 2230955-40.2016.8.26.0000. Relator: Des. Percival Nogueira, 17 de fevereiro de 2017. Disponível em: https://esaj.tjsp.jus.br/cjsg/getArquivo.do?cdAcordao=10182148\&cdForo=0. Acesso em: 27 maio 2021.

BRASIL. Tribunal de Justiça do Estado de São Paulo (26. Câmara de Direito Privado). Apelação Cível 0006507-39.2013.8.26.0222. Relator: Des. Antonio Nascimento, 2 de fevereiro de 2017. Disponível em: https://esaj.tjsp.jus.br/cjsg/getArquivo.do?cdAcordao=10123615\&cdForo=0. Acesso em: 27 maio 2021.

BRASIL. Tribunal de Justiça do Estado de São Paulo (2. Câmara de Direito Privado). Apelação Cível 101726712.2017.8.26.0506. Relator: Des. José Joaquim dos Santos, 11 de setembro de 2018. Disponível em: https:// esaj.tjsp.jus.br/cjsg/getArquivo.do?cdAcordao=11809380\&cdForo=0. Acesso em: 26 maio 2021.

BRASIL. Tribunal de Justiça do Estado de São Paulo (4. Câmara de Direito Privado). Apelação Cível 1083843-12.2015.8.26.0100. Relator: Des. Hamid Bdine, 11 de agosto de 2016. Disponível em: https:// esaj.tjsp.jus.br/cjsg/getArquivo.do?cdAcordao=9699652\&cdForo=0. Acesso em: 26 maio 2021.

BRASIL. Tribunal de Justiça do Estado de São Paulo (21. Câmara de Direito Privado). Embargos de Declaração Cível no Agravo de Instrumento 2077958-72.2016.8.26.0000. Relator: Des. Virgilio de Oliveira Junior, 9 de outubro de 2017. Disponível em: https://esaj.tjsp.jus.br/cjsg/getArquivo. do? cdAcordao $=10870499 \&$ cdForo $=0$. Acesso em: 27 maio 2021 . 


\section{Legislação citada}

BRASIL. [Constituição (1891)]. Constituição da República dos Estados Unidos do Brasil (de 24 de fevereiro de 1891. Brasília: Presidência da República, [1926]. Disponível em: https:// www.planalto.gov.br/ccivil_03/constituicao/constituicao91.htm. Acesso em: 18 abr. 2021.

BRASIL. [Constituição (1988)]. Constituição da República Federativa do Brasil de 1988. Brasília: Presidência da República, [2021]. Disponível em: https://www.planalto.gov.br/ ccivil_03/constituicao/constituicao.htm. Acesso em: 20 fev. 2021.

BRASIL. Lei no 5.250, de 9 de fevereiro de 1967. Regula a liberdade de manifestação do pensamento e de informação. Brasília: Presidência da República, [1985]. Disponível em: https://www.planalto.gov.br/ccivil_03/leis/15250.htm. Acesso em: 18 abr. 2021.

BRASIL. Lei no 9.610, de 19 de fevereiro de 1998. Altera, atualiza e consolida a legislação sobre direitos autorais e dá outras providências. Brasília: Presidência da República, [2013]. Disponível em: https://www.planalto.gov.br/ccivil_03/leis/19610.htm. Acesso em: 18 abr. 2021.

BRASIL. Lei no 12.965, de 23 de abril de 2014. Estabelece princípios, garantias, direitos e deveres para o uso da Internet no Brasil. Brasília: Presidência da República, [2014]. Marco civil da Internet. Disponível em: https://www.planalto.gov.br/ccivil_03/_ato2011-2014/2014/lei/ 112965.htm. Acesso em: 18 abr. 2021. 